\title{
Effects of different swimming race constraints on turning movements
}

\author{
Santiago Veiga ${ }^{\mathrm{a}, \mathrm{b}, *}$, Javier Mallo $^{\mathrm{b}}$, Archit Navandar $^{\mathrm{b}}$, Enrique Navarro ${ }^{\mathrm{b}}$ \\ ${ }^{a}$ Madrid Swimming Federation, C/ José Martinez Velasco, 3, 28007 Madrid, Spain \\ ${ }^{\mathrm{b}}$ Technical University of Madrid, Health and Human Performance Department, C/ Martín Fierro, 7, 28040 Madrid, Spain
}

\section{A R T I C L E I N F O}

\section{Article history:}

Available online 27 May 2014

\section{PsycINFO classification:}

3700

\section{Keywords:}

Kinematic analysis

Underwater

Performance

Skill

\begin{abstract}
A B S T R A C T
The aim of this study was to investigate the effects of different swimming race constraints on the evolution of turn parameters. One hundred and fifty-eight national and regional level 200-m (meters) male swimming performances were video-analyzed using the individualized-distance model in the Open Comunidad de Madrid tournament. Turn $(p<.001, \mathrm{ES}=0.36)$ and underwater distances $(p<.001, \mathrm{ES}=0.38)$ as well as turn velocity $(p<.001$, $\mathrm{ES}=0.69$ ) significantly dropped throughout the race, although stroke velocity and underwater velocity were maintained in the last lap of the race $(p>.05)$. Higher expertise swimmers obtained faster average velocities and longer distances in all the turn phases $(p<.001, \mathrm{ES}=0.59)$, except the approach distance. In addition, national level swimmers showed the ability to maintain most of the turn parameters throughout the race, which assisted them in improving average velocity at the end of races. Therefore, the variations in the turning movements of a swimming race were expertise-related and focused on optimizing average velocity. Turning skills should be included in the swimming race action plan.
\end{abstract}

(C) 2014 Elsevier B.V. All rights reserved.

\section{Introduction}

In competitive swimming, both underwater and surface swimming techniques (Cohen, Cleary, \& Mason, 2012) are employed by competitors to overcome the aquatic constraints that impose forward

* Corresponding author at: Madrid Swimming Federation, C/ José Martinez Velasco, 3, 28007 Madrid, Spain. Tel.: +34 616001953.

E-mail address: santi.veiga@fmn.es (S. Veiga). 
resistance (Toussaint \& Beek, 1992; Toussaint, Roos, \& Kolmogorov, 2004). Underwater swimming allows competitors to minimize their velocity loss after dives and turns (Connaboy, Coleman, Moir, \& Sanders, 2010) as far as a maximum of 15 -m from the starting or turning walls. In most cases, this is achieved by minimizing the resisted drag forces with a streamlined body position (Lyttle, Blanksby, Elliott, \& Lloyd, 1998) and by maximizing propulsion with the swimmer's feet moving simultaneously in vertically-oriented motions (Von Loebbecke, Mittal, Mark, \& Hahn, 2009), in an underwater undulatory stroke (Connaboy, Coleman, \& Sanders, 2009). Compared to surface swimming, forward velocities during underwater swimming are greater (Vennell, Pease, \& Wilson, 2006) whereas kinematics are significantly simpler (von Loebbecke, Mittal, Mark, et al., 2009). On the other hand, physical exertion is probably greater for the swimmer due to apnea conditions.

The analyses of swimmers' performances have traditionally examined spatio-temporal parameters representing the starting, stroking and turning segments in a swimming race (Arellano, Brown, Cappaert, \& Nelson, 1994) but, somehow, have overlooked the role of underwater swimming techniques. Researchers and/or practitioners have measured partial times at 5, 10, 15 or 25-m intervals from the starting or turning walls and have evaluated how different swimming constraints, such as increasing fatigue, affect their evolution throughout races (de Jesus et al., 2012; Figueiredo, Rouard, Vilas-Boas, \& Fernandes, 2013; Figueiredo, Zamparo, Sousa, Vilas-Boas, \& Fernandes, 2011; Hellard et al., 2008; Suito et al., 2008; Toussaint, Carol, Kranenborg, \& Truijens, 2006). However, temporal race parameters do not discriminate between submerged and surface techniques and it cannot be assumed that swimmers travel the same distances with starting, turning or stroking movements (Veiga, Cala, Mallo, \& Navarro, 2013). In fact, the limitations of quantifying only traditional race parameters have been increasingly recognized in recent years (Psycharakis, Naemi, Connaboy, McCabe, \& Sanders, 2010).

Underwater swimming techniques, such as the undulatory swimming or the breaststroke pullout with dolphin kick (McLean, Havriluk, \& Brandt, 2008) are relatively new in competitive swimming (Arellano, Pardillo, \& Gavilán, 2002; Von Loebbecke, Mittal, Fish, \& Mark, 2009). However, at present, there is a growing research interest in these competitive techniques (Connaboy et al., 2010; Hochstein \& Blickhan, 2011; Puel et al., 2012) as they are supposed to provide a competitive edge to swimmers (Atkinson, Dickey, Dragunas, \& Nolte, 2014; von Loebbecke, Mittal, Fish, et al., 2009). Several factors have been reported to affect the effectiveness of underwater undulatory swimming, including the kick frequency (Cohen et al., 2012), amplitude (Houel, Elipot, André, \& Hellard, 2013), symmetry (Atkinson et al., 2014) and swimmer morphology (von Loebbecke, Mittal, Fish, et al., 2009). Distances traveled with underwater movements have been found relevant to the starting and turning (Blanksby, Elliott, McElroy, \& Simpson, 1998; Tourny-Chollet, Chollet, Hogie, \& Papparodopoulos, 2002) competitive performances. However, it is unknown how swimmers organize the underwater or surface components during a swimming race or how various competitive swimming constraints (like the number of laps, gender, expertise or event stroke) could influence the underwater swimming parameters. Previous research studies have reported that skilled swimmers exhibited more stable stroking parameters and average velocities (Chollet, Pelayo, Delaplace, Tourny, \& Sidney, 1997; Figueiredo et al., 2011; Hellard et al., 2008) in 100 and 200-m freestyle races, although there is still a lack of knowledge if this skill issue is also present during non-swimming segments.

Therefore, in the present study we employed the individualized-distance method to detect the underwater and surface components of swimming races. The main aim of the investigation was to examine the effects of different swimming race constraints (lap, stroke and swimmers expertise) on the evolution of individualized-distance turn parameters. It was hypothesized that the turning parameters might be related to the swimmer's ability.

\section{Methods}

\subsection{Participants}

One hundred and fifty-eight male swimming performances were video-analyzed in the 200-m final events of the 2008 Open Comunidad de Madrid, an international competition organized by the Madrid 
Swimming Federation in a $50 \times 25$-m pool (eight lanes). Before the commencement of the competition written consent was obtained from all the team managers to video-analyze the races. Final times were classified as national or regional level performances according to the 2008 Spanish Swimming Federation National Standards (200-m breaststroke: 147.30 s (seconds); $200-\mathrm{m}$ freestyle: $116.20 \mathrm{~s} ; 200-\mathrm{m}$ backstroke: $133.50 \mathrm{~s}$ and 200 -m butterfly: $130.15 \mathrm{~s}$ ). In total, 70 national level performances (Fédération Internationale de Natation [FINA] Point Scoring System $768.6 \pm 41.33$ ) and 88 regional level (FINA Point Scoring System $645.3 \pm 58.73$ ) were analyzed in the four strokes. All experimental procedures were reviewed and approved by the Technical University of Madrid's ethics committee.

\subsection{Data collection}

Two fixed JVC ${ }^{\circledR}$ GY-DV500E video cameras were located on the top row of spectator seats, approximately 7-m above and 7-m away from the side of the pool. Each camera operated at a frame rate of $25 \mathrm{~Hz}$ with a shutter speed of $1 / 1000 \mathrm{~s}$ and captured a different part of the race corresponding to the first or the last $15-\mathrm{m}$, respectively, from the starting blocks. A flashlight connected to the official timing system was captured by the cameras to provide the race's time code.

\subsection{Data processing}

Selected two-dimensional coordinates of the swimming races were obtained using DLT algorithms (Abdel-Aziz \& Karara, 1971). Eight poolside building marks in the field of view of each camera provided control points for the calibration of the swimmer's plane of movement during the races. A different set of 32 control points constituted by colored buoys from the floating lanes were employed to check the 2D coordinate reconstruction (accuracy) in the field of view of each camera, showing a root mean square error of less than $0.05-\mathrm{m}$. More data related to the validation process can be obtained in Veiga, Cala, González Frutos, and Navarro (2010). The video footage of the races was digitized to identify swimmers' movements according to the individualized-distance model (Veiga et al., 2013) with the software Photo 23D (Technical University of Madrid, Spain; Cala, Veiga, García, \& Navarro, 2009). The turn segment was defined including two different phases: the turn approach phase, from the swimmer's last stroke to wall contact, and the turn underwater phase, from wall contact to the swimmer's breakout after the underwater swim. On the other hand, the stroking phase was defined from the end of an underwater turn phase to the beginning of the next turn approach. In the first race lap, the stroking phase was measured from the swimmer's breakout after the starting phase. The instants of the swimmer's last stroke and the swimmer's breakout were represented by the first moment the hand entered the water and the vertex of the head emerging from the water, respectively. In breaststroke races, the swimmer's last stroke was defined as the last head emersion before the turning wall, as no hand entry occurs. Finally, the official electronic timing system allowed us to detect the instant of the wall contact and to calculate average lap velocities from the official lap times of each event. After selected two-dimensional coordinates of the race were obtained, the horizontal distance ( $\mathrm{m})$ movement of the swimmer's head from the beginning to the end of the turn and stroking phases, time $(\mathrm{s})$ and average velocity $(\mathrm{m} / \mathrm{s})$ were calculated.

Once the individualized-distance turn parameters of the $200-\mathrm{m}$ races were obtained, the traditional $15-\mathrm{m}$ turn times were also measured by overlaying digital lines on the image. The control points employed for the two-dimensional coordinate reconstruction served as a reference in the images for placing the digital lines at exactly $7.5-\mathrm{m}$ from the turning wall.

\subsection{Data analysis}

The individualized-distance turn parameters (turn distance, turn velocity, approach distance, approach velocity, underwater distance and underwater velocity), as well as the stroking and lap average velocities and the $15-\mathrm{m}$ turn times, were analyzed by the expertise of the swimmers (national and regional level), the event stroke (breaststroke, freestyle, backstroke and butterfly) and the turn or lap order (first to third turn or first to fourth stroking lap in a 200-m race) using a repeated measures multivariate analysis of variance with the multivariate mixed model (Schutz \& Gessaroli, 1987). Wilks' 
lambda was used to detect the main effects of the race constraints. Bonferroni adjustments were employed to make multiple comparisons between inter- and intra-subject groups, and effect sizes (as partial eta-squared values) were used to interpret meaningful effects (Knudson, 2009). Distances and velocities were expressed as means \pm standard deviations (s) and the level of statistical significance was set at .05. All statistical analyses were conducted with SPSS 15.0 (SPSS Inc., Chicago, IL, USA).

\section{Results}

\subsection{Effects of the task constraints (event stroke and turn order) on the turn parameters}

The turn order (Wilks' lambda $=0.26, F_{14,588}=41.01, p<.001$, ES $=0.50$ ) and the event stroke (Wilks' lambda $=0.02, F_{21,414.04}=148.54, p<.001, E S=0.87$ ), representing task constraints for competitive swimmers, influenced the individualized-distance turn parameters. The $15-\mathrm{m}$ turn time increased $(p<.001$, ES $=0.67$; first to second turn $3.82 \%$, second to third turn $1.90 \%)$, whereas the turn distance $(p<.001$, ES $=0.36$; first to second turn $6.22 \%$, second to third turn $2.22 \%)$ and the turn velocity $(p<.001$, ES $=0.69$; first to second turn $3.55 \%$, second to third turn $1.80 \%)$ decreased in each turn of the race. Fig. 1 illustrates the evolution of distance and velocity parameters in the turn phases (approach and underwater) during the 200-m races.

All the turn parameters were significantly different depending on the event stroke, except for the butterfly and backstroke underwater distances $(p=.19)$ and for the backstroke and freestyle approach velocities $(p=.73)$. However, the evolution of the turn parameters was similar in all strokes except for the freestyle races (stroke $\times$ turn order, Wilks' lambda $=0.25, F_{42,1382.43}=11.36, p<.001$, ES $=0.21$ ),



Fig. 1. Evolution of the turn phase parameters in the $200-\mathrm{m}$ swimming races. Significant differences with the previous turn: ${ }^{*} p<.05$. 
where no underwater velocity or distance variations occurred throughout the freestyle races (both $p>.05$ from first to second and from second to third turn).

\subsection{Effects of the organismic constraints (expertise) on the turn parameters}

The turn parameters also varied according to the swimmer's expertise (Wilks' lambda $=0.42$, $F_{7,144}=28.71, p<.001, \mathrm{ES}=0.59$ ). National level swimmers obtained $6.67 \%$ shorter $15-\mathrm{m}$ turn times $(p<.001$, ES $=0.54)$ as well as $5.96 \%$ faster turn velocities $(p<.001, \mathrm{ES}=0.59)$ and $6.73 \%$ longer turn distances $(p<.001$, ES $=0.11)$ than regional level swimmers. In the turn phases, higher expertise swimmers obtained higher underwater $(p<.001, \mathrm{ES}=0.10)$ and approach $(p<.01, \mathrm{ES}=0.06)$ velocities. In addition, longer underwater $(p<.001, \mathrm{ES}=0.11)$, but not longer $(p=.68)$ approach distances, were obtained by higher expertise swimmers in the turn phases. Inter-level differences in the turn parameters depended on the event stroke (expertise $\times$ stroke, Wilks' lambda $=0.45, F_{21,414.04}=6.38, p<.001$, $\mathrm{ES}=0.24)$ as significant distinctions $(p<.05)$ were detected in the butterfly velocity and breaststroke distance approach parameters, whereas no differences $(p>.05)$ were detected in any of the freestyle turn distance parameters. Descriptive data, as well as inter-level comparisons of the individualizeddistance turn phase parameters in all strokes, are presented in Table 1.

General differences between national and regional level swimmers in all the turn parameters (except for the approach distance) persisted in each turn of the race $(p<.05)$. However, there was a significant interaction (expertise $\times$ turn order $\times$ stroke, Wilks' lambda $=0.79, \quad F_{42.1382 .43}=1.675$, $p<.01$, ES $=0.04$ ) showing that, in comparison to the national level, regional level swimmers lost underwater turn velocity (both $p<.05$ in the second and third turn) throughout the breaststroke and butterfly races and turn velocity at the end of backstroke and butterfly races $(p<.05$ in the last turn). Lower expertise swimmers also shortened the underwater turn distance during breaststroke races (both the second and third turn, $p<.05)$ and during the last backstroke turn $(p<.05)$ in comparison to higher expertise swimmers. Tables 2 and 3 show the evolution of the individualized-distance turn parameters throughout the race for each group.

\subsection{Effects of the swimming race constraints on the stroking parameters}

Finally, national level swimmers obtained 5.63\% faster stroking velocities than regional level swimmers $(p<.001, \mathrm{ES}=0.59)$, regardless of the stroke (level $\times$ stroke, $p=.29, \mathrm{ES}=0.03)$. The stroking velocity significantly decreased by $5.61 \%(p<.001$, ES $=0.71)$ from the first to second and $1.79 \%$ from

Table 1

Comparison of the turn phase parameters between national and regional level swimmers.

\begin{tabular}{|c|c|c|c|c|c|}
\hline & & & Approach phase & Underwater phase & Total turn \\
\hline \multirow{8}{*}{ Distance } & \multirow{2}{*}{ Breaststroke } & National & $2.08 \pm 0.37$ & $8.23 \pm 0.90^{*}$ & $10.31 \pm 1.02^{*}$ \\
\hline & & Regional & $2.05 \pm 0.28$ & $7.61 \pm 0.68$ & $9.66 \pm 0.77$ \\
\hline & \multirow[t]{2}{*}{ Freestyle } & National & $1.80 \pm 0.29$ & $4.81 \pm 0.71$ & $6.60 \pm 0.81$ \\
\hline & & Regional & $1.81 \pm 0.27$ & $4.52 \pm 0.65$ & $6.33 \pm 0.73$ \\
\hline & \multirow{2}{*}{ Backstroke } & National & $2.73 \pm 0.30$ & $6.25 \pm 0.73^{*}$ & $8.97 \pm 0.83^{*}$ \\
\hline & & Regional & $2.63 \pm 0.26$ & $5.81 \pm 0.63$ & $8.44 \pm 0.72$ \\
\hline & \multirow[t]{2}{*}{ Butterfly } & National & $1.63 \pm 0.37^{*}$ & $6.68 \pm 0.90^{*}$ & $8.31 \pm 1.02^{* *}$ \\
\hline & & Regional & $1.40 \pm 0.24$ & $6.08 \pm 0.58$ & $7.47 \pm 0.65$ \\
\hline \multirow[t]{8}{*}{ Velocity } & \multirow[t]{2}{*}{ Breaststroke } & National & $1.70 \pm 0.19^{* *}$ & $1.52 \pm 0.15$ & $1.49 \pm 0.06^{* * *}$ \\
\hline & & Regional & $1.51 \pm 0.15$ & $1.48 \pm 0.11$ & $1.37 \pm 0.04$ \\
\hline & \multirow[t]{2}{*}{ Freestyle } & National & $1.27 \pm 0.15$ & $2.59 \pm 0.12^{*}$ & $1.85 \pm 0.04^{* * *}$ \\
\hline & & Regional & $1.25 \pm 0.14$ & $2.14 \pm 0.11$ & $1.77 \pm 0.04$ \\
\hline & \multirow[t]{2}{*}{ Backstroke } & National & $1.24 \pm 0.16$ & $2.21 \pm 0.12^{*}$ & $1.69 \pm 0.05^{* * *}$ \\
\hline & & Regional & $1.17 \pm 0.14$ & $2.14 \pm 0.10$ & $1.59 \pm 0.04$ \\
\hline & \multirow[t]{2}{*}{ Butterfly } & National & $1.79 \pm 0.19$ & $1.63 \pm 0.15^{* *}$ & $1.59 \pm 0.06^{* * *}$ \\
\hline & & Regional & $1.77 \pm 0.12$ & $1.51 \pm 0.09$ & $1.50 \pm 0.04$ \\
\hline
\end{tabular}

Significant differences between levels: ${ }^{*} p<.05 ;{ }^{* *} p<.01 ;{ }^{* * *} p<.001$. 


\section{Table 2}

Evolution of the individualized-distance turn phase velocities in national and regional level swimmers.

\begin{tabular}{|c|c|c|c|c|c|}
\hline & & & I & II & III \\
\hline \multirow{8}{*}{ Underwater velocity } & \multirow[t]{2}{*}{ Breaststroke } & National & $1.55 \pm 0.17$ & $1.51 \pm 0.15$ & $1.50 \pm 0.18$ \\
\hline & & Regional & $1.53 \pm 0.13$ & $1.42 \pm 0.12^{\mathrm{a}}$ & $1.48 \pm 0.14^{\mathrm{a}}$ \\
\hline & \multirow[t]{2}{*}{ Freestyle } & National & $2.58 \pm 013$ & $2.59 \pm 0.12$ & $2.61 \pm 0.15$ \\
\hline & & Regional & $2.54 \pm 0.12$ & $2.52 \pm 0.11$ & $2.50 \pm 0.13$ \\
\hline & \multirow[t]{2}{*}{ Backstroke } & National & $2.21 \pm 0.14$ & $2.20 \pm 0.13$ & $2.21 \pm 0.15$ \\
\hline & & Regional & $2.12 \pm 0.12$ & $2.16 \pm 0.11$ & $2.14 \pm 0.13$ \\
\hline & \multirow[t]{2}{*}{ Butterfly } & National & $1.66 \pm 0.17$ & $1.59 \pm 0.15$ & $1.65 \pm 0.18$ \\
\hline & & Regional & $1.58 \pm 0.11$ & $1.46 \pm 0.10^{\mathrm{a}}$ & $1.50 \pm 0.12^{\mathrm{a}}$ \\
\hline \multirow[t]{8}{*}{ Turn velocity } & \multirow[t]{2}{*}{ Breaststroke } & National & $1.53 \pm 0.06$ & $1.49 \pm 0.07^{\mathrm{a}}$ & $1.45 \pm 0.07^{\mathrm{a}, \mathrm{b}}$ \\
\hline & & Regional & $1.44 \pm 0.04$ & $1.36 \pm 0.05^{\mathrm{a}}$ & $1.33 \pm 0.05^{\mathrm{a}, \mathrm{b}}$ \\
\hline & \multirow[t]{2}{*}{ Freestyle } & National & $1.90 \pm 0.04$ & $1.85 \pm 0.05^{\mathrm{a}}$ & $1.81 \pm 0.05^{\mathrm{a}, \mathrm{b}}$ \\
\hline & & Regional & $1.83 \pm 0.04$ & $1.76 \pm 0.05^{\mathrm{a}}$ & $1.73 \pm 0.05^{\mathrm{a}, \mathrm{b}}$ \\
\hline & \multirow[t]{2}{*}{ Backstroke } & National & $1.74 \pm 0.04$ & $1.67 \pm 0.06^{\mathrm{a}}$ & $1.65 \pm 0.06^{\mathrm{a}}$ \\
\hline & & Regional & $1.65 \pm 0.04$ & $1.57 \pm 0.05^{\mathrm{a}}$ & $1.54 \pm 0.05^{\mathrm{a}, \mathrm{b}}$ \\
\hline & \multirow{2}{*}{ Butterfly } & National & $1.62 \pm 0.06$ & $1.59 \pm 0.07^{\mathrm{a}}$ & $1.58 \pm 0.07^{\mathrm{a}}$ \\
\hline & & Regional & $1.56 \pm 0.04$ & $1.49 \pm 0.04^{\mathrm{a}}$ & $1.46 \pm 0.04^{\mathrm{a}, \mathrm{b}}$ \\
\hline
\end{tabular}

${ }_{\mathrm{a}, \mathrm{b}}$ Statistically different from first and second turn, respectively: $p<.05$.

Table 3

Evolution of the turn phase distances in national and regional level swimmers.

\begin{tabular}{|c|c|c|c|c|c|}
\hline & & & I & II & III \\
\hline \multirow[t]{8}{*}{ Underwater distance } & \multirow[t]{2}{*}{ Breaststroke } & National & $8.57 \pm 1.07$ & $8.21 \pm 0.91$ & $7.90 \pm 0.96$ \\
\hline & & Regional & $7.96 \pm 0.81$ & $7.76 \pm 0.69$ & $7.12 \pm 0.73^{\mathrm{a}, \mathrm{b}}$ \\
\hline & \multirow[t]{2}{*}{ Freestyle } & National & $5.00 \pm 0.85$ & $4.77 \pm 0.72$ & $4.66 \pm 0.76^{\mathrm{a}}$ \\
\hline & & Regional & $4.67 \pm 0.78$ & $4.50 \pm 0.65$ & $4.39 \pm 0.69^{a}$ \\
\hline & \multirow[t]{2}{*}{ Backstroke } & National & $6.61 \pm 0.88$ & $6.20 \pm 0.74^{\mathrm{a}}$ & $5.93 \pm 0.78^{a}$ \\
\hline & & Regional & $6.30 \pm 0.76$ & $5.69 \pm 0.64^{\mathrm{a}}$ & $5.42 \pm 0.68^{\mathrm{a}, \mathrm{b}}$ \\
\hline & \multirow[t]{2}{*}{ Butterfly } & National & $7.12 \pm 1.07$ & $6.50 \pm 0.91^{\mathrm{a}}$ & $6.43 \pm 0.96^{\mathrm{a}}$ \\
\hline & & Regional & $6.27 \pm 0.69$ & $6.06 \pm 0.58^{\mathrm{a}}$ & $5.90 \pm 0.62^{\mathrm{a}}$ \\
\hline \multirow[t]{8}{*}{ Turn distance } & \multirow[t]{2}{*}{ Breaststroke } & National & $10.80 \pm 1.22$ & $10.40 \pm 1.10$ & $9.73 \pm 1.10^{\mathrm{a}, \mathrm{b}}$ \\
\hline & & Regional & $10.06 \pm 0.92$ & $9.86 \pm 0.83$ & $9.08 \pm 0.83^{\mathrm{a}, \mathrm{b}}$ \\
\hline & \multirow[t]{2}{*}{ Freestyle } & National & $6.88 \pm 0.97$ & $6.38 \pm 0.87^{a}$ & $6.56 \pm 0.87$ \\
\hline & & Regional & $6.56 \pm 0.88$ & $6.16 \pm 0.79^{a}$ & $6.27 \pm 0.79$ \\
\hline & \multirow[t]{2}{*}{ Backstroke } & National & $9.52 \pm 1.00$ & $8.63 \pm 0.90^{\mathrm{a}}$ & $8.76 \pm 0.90$ \\
\hline & & Regional & $9.13 \pm 0.86$ & $8.06 \pm 0.78^{\mathrm{a}}$ & $8.12 \pm 0.78$ \\
\hline & \multirow{2}{*}{ Butterfly } & National & $8.78 \pm 1.22$ & $8.25 \pm 1.10$ & $7.91 \pm 1.10^{\mathrm{a}}$ \\
\hline & & Regional & $7.74 \pm 0.79$ & $7.41 \pm 0.71$ & $7.27 \pm 0.71^{\mathrm{a}}$ \\
\hline
\end{tabular}

${ }^{\mathrm{a}, \mathrm{b}}$ Statistically different from first and second turn, respectively: $p<.05$.

the second to the third lap, but was maintained in the last lap of the races $(p<.05)$ for both expertise levels. Similar inter-level differences $(5.74 \%$ from national to regional level swimmers; $p<.001$, $\mathrm{ES}=0.63)$ as well as a similar evolutions throughout the race $(9.56 \%$ from the first to second and $1.94 \%$ from the second to the third lap; $p<.001$, ES $=0.88$ ) were observed for the lap velocities, except in the last lap of the race where higher level swimmers increased their average velocity by $0.85 \%$ $(p<.05)$. Fig. 2 illustrates the evolution of both the stroking and lap velocity throughout the race for both levels.

\section{Discussion}

The present study aimed at examining the effects of different swimming race constraints on turn parameters. In general, underwater distances decreased throughout the race whereas underwater velocities were maintained, although their evolution depended on the stroke and the swimmer's level 


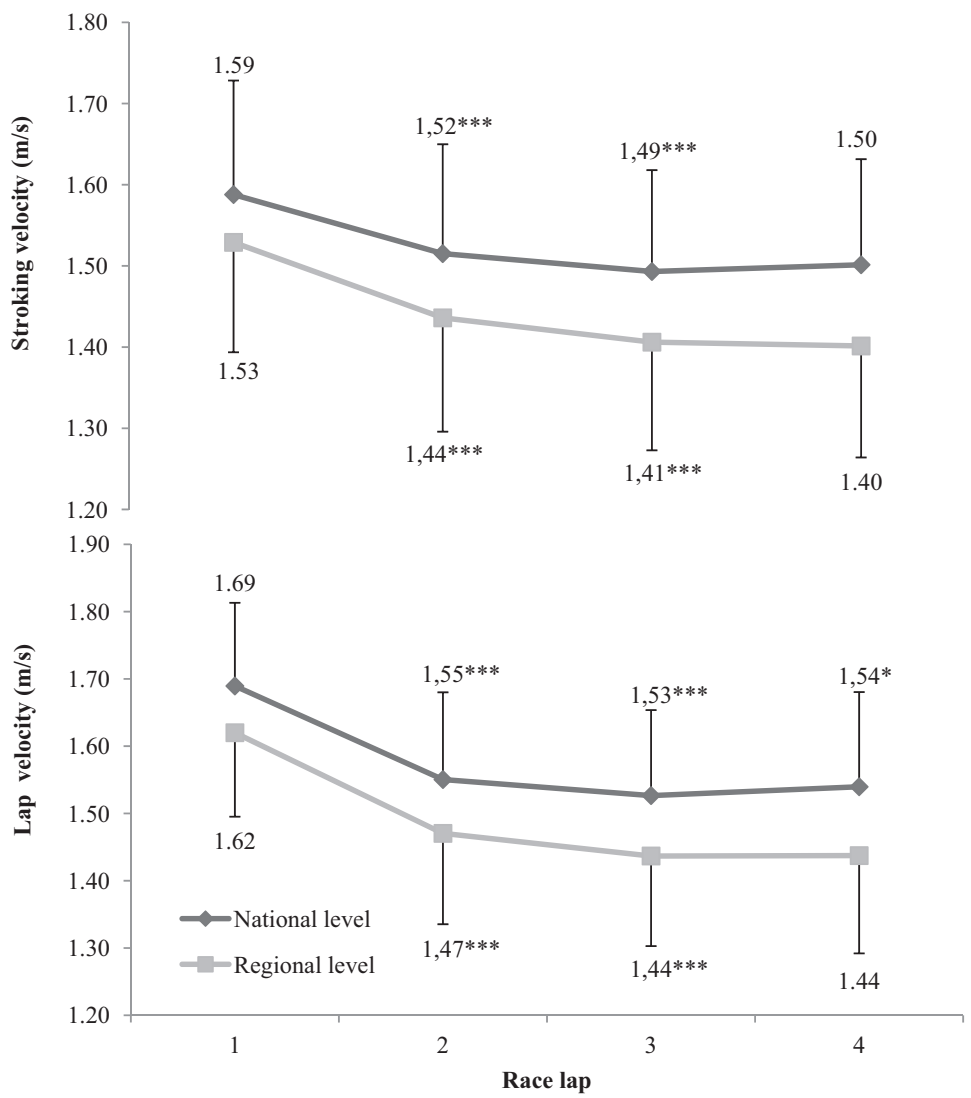

Fig. 2. Lap and stroking velocity evolution in the 200-m swimming races for the national and regional level swimmers. Significant differences with the previous lap: ${ }^{*} p<.05 ;{ }^{* *} p<.01 ;{ }^{* * *} p<.001$.

of skill. The use of the individualized-distance method allowed, for the first time ever, the detection and comparison of the underwater and surface components of a swimming race.

The first important observation was that turn and underwater distances were different depending on the stroke, except for the backstroke and butterfly races where swimmers employed underwater undulatory movements to travel around 5-m. Therefore, it should be considered whether it is appropriate to measure the same fixed distance (for example $15-\mathrm{m}$ turn time) to evaluate all swimming races, as this would not reflect the swimmer's different solutions in terms of underwater swimming or stroking.

The second important observation was that swimmers not only modified their stroking parameters during the same race (Chollet et al., 1997; Hellard et al., 2008; Suito et al., 2008; Thompson, Haljand, \& MacLaren, 2000), but also modified most of their turning parameters. Despite traditional swimming race analyses measuring fixed 15-m turn times regardless of the race lap (Arellano et al., 1994; Thompson et al., 2000; Tourny-Chollet et al., 2002), the turn and underwater distances in the present study generally dropped throughout the race (Fig. 1 and Table 1), probably due to fatigue (Figueiredo et al., 2011; Toussaint et al., 2006) and the hypoxic conditions of the underwater swimming. The decrement in underwater distance from the first to the third turn of the race $(0.6-0.8-\mathrm{m})$ represented approximately the distance covered when performing one dolphin kick (Zamparo, Vicentini, Scattolini, Rigamonti, \& Bonifazi, 2012). On the other hand, the underwater velocities were maintained in most of the cases (Table 2), which may suggest a tactical issue where swimmers shortened the 
underwater distance as the race progressed to optimize their velocity. Regarding the approach parameters, there was no clear tendency throughout the race, which could have been related to the changing technical timing of the final strokes before wall contact (Seifert, Boulesteix, Carter, \& Chollet, 2005; Veiga et al., 2013).

In the freestyle races, where the underwater phase is shorter (Table 1) and the undulatory techniques do not seem to be extensively used by intermediate level swimmers, most of the turning parameters did not vary throughout the races. The specific characteristics of the freestyle stroke (alternate arm actions and a profiled body position) may ensure a continuous propulsion at low energy cost (Wakayoshi, D'Acquisto, Cappaert, \& Troup, 1995) and, therefore, freestyle swimmers may be able to modify their stroking parameters during the race to maintain average velocities (Huot-Marchand, Nesi, Sidney, Alberty, \& Pelayo, 2005).

When comparing the two levels of expertise, higher expertise swimmers reached longer underwater distances (except in the freestyle event) than lower expertise swimmers (Table 1), either because they exploited the breaststroke gliding phases (Seifert, Vantorre, \& Chollet, 2007) or the backstroke and butterfly underwater undulatory movements (Vantorre, Seifert, Fernandes, Vilas Boas, \& Chollet, 2010b). Interestingly, they also obtained faster underwater turn velocities in all events except breaststroke, even though it has been previously explained that this parameter is only important for the start performance (Burkett, Mellifont, \& Mason, 2010; Cossor \& Mason, 2001; Vantorre, Seifert, Fernandes, Vilas Boas, \& Chollet, 2010a). Finally, they showed the ability to stabilize some of the turn parameters throughout the race compared to the lower expertise swimmers (Tables 2 and 3). This could represent a clear strategy to optimize average velocity at the end of a race as national level swimmers maintained the underwater turn distance when using the slowest techniques (backstroke and breaststroke) and the turn velocity in the techniques employing underwater undulatory movements (backstroke and butterfly). Previous research studies reported that higher expertise swimmers obtained shorter 15-m turn times at the end of the 200-m backstroke (Chatard, Girold, Cossor, \& Mason, 2001a), breaststroke (Thompson et al., 2000) butterfly (Tourny-Chollet et al., 2002) and freestyle (Chatard, Girold, Cossor, \& Mason, 2001b), but no further explanations about the underlying reasons had ever been reported.

From a traditional motor control perspective, regional level swimmers may have made mistakes when traveling shorter distances underwater. However, they may have also organized their competitive turns according to their lower levels of gliding skills (Kolmogorov, Rumyantseva, Gordon, \& Cappaert, 1997) and muscular power (Wakayoshi, Yoshida, Ikuta, Mutoh, \& Miyashita, 1993). Taking into account that the 200-m event is considered to be exhausting (Bonifazi, Martelli, Marugo, Sardella, \& Carli, 1993; Figueiredo et al., 2011, 2013), they may not have been able to maintain apnea conditions at the end of the race like the national level swimmers did. On the other hand, national level swimmers obtained a more consistent turn performance, which may be optimal in swimming, where a high level of precision is required and unexpected changes in competitive conditions rarely occur (Hiley, Zuevsky, \& Yeadon, 2013). Further research would be needed to explore if elite swimmers might even shown higher or lower variations in turning parameters throughout races (Wilson, Simpson, Van Emmerik, \& Hamill, 2008).

Finally, differences in the evolution of the stroking and turning parameters provided important functional information about the swimmers' performances. Both national and regional level swimmers maintained their stroking velocities at the end of races, probably by increasing their stroking rates to improve propulsion (Huot-Marchand et al., 2005; Thompson et al., 2000). However, by maintaining some of the last turn parameters (Tables 2 and 3), higher level swimmers were able to increase their average velocity in the last lap of the race (Fig. 2). On the other hand, regional level swimmers probably had to conserve their energy during the last turn in order to be able to maintain their stroking velocity at the end of the race. This might have had a crucial impact on the final race outcome (Chatard, Girold, Caudal, Cossor, \& Mason, 2003) and could confirm that a higher consistency in the turning movements is beneficial for intermediate level swimmers.

At this point, the way competitors organize the underwater or surface components of a swimming race seems to be appropriate to a swimmer's skill level and also to the stroke. There does not seem to be an ideal turn motor pattern for 200-m competitive swimming. However, swimmers must organize their turning movements by determining the optimal underwater distance in order to maximize 
underwater velocity. These actions will assist them to optimize their average race velocities, especially at the end of the events. Intermediate level swimmers are encouraged to focus on tasks concerning gliding skills, underwater undulatory movement and the transition to the stroking phase. As they improve their expertise level they are advised to include the underwater skills in their strategic race action plan.

\section{Conclusion}

The turning movements showed variations in a swimming race which were dependent on the swimmer's level of expertise and focused on optimizing average velocity. Except in the freestyle events, higher-expertise performers traveled a longer portion of the race underwater and exhibited a more consistent turn performance than lower-expertise swimmers, especially at the end of the races. Therefore, turning skills should be included in the strategic swimming race action plan.

\section{References}

Abdel-Aziz, Y. I., \& Karara, H. M. (1971). Direct linear transformation from comparator coordinates into space coordinates in close-range photogrammetry. In American Society of Photogrammetry (Ed.), Proceedings of the symposium on close-range photogrammetry (pp. 1-18). Falls-Church, VA: American Society of Photogrammetry.

Arellano, R., Pardillo, S., \& Gavilán, A. (2002). Underwater undulatory swimming: Kinematic characteristics, vortex generation and application during start, turn and swimming strokes. In XXth international symposium on biomechanics in sports - applied program - swimming. Cáceres: Universidad de Extremadura.

Arellano, R., Brown, P., Cappaert, J., \& Nelson, R. C. (1994). Analysis of 50-, 100-, and 200-m freestyle swimmers at the 1992 Olympic games. Journal of Applied Biomechanics, 10(2), 189-199.

Atkinson, R. R., Dickey, J. P., Dragunas, A., \& Nolte, V. (2014). Importance of sagittal kick symmetry for underwater dolphin kick performance. Human Movement Science, 33(1), 298-311.

Blanksby, B. A., Elliott, B. C., McElroy, K., \& Simpson, J. R. (1998). Biomechanical factors influencing breaststroke turns by agegroup swimmers. Journal of Applied Biomechanics, 14(2), 180-189.

Bonifazi, M., Martelli, G., Marugo, L., Sardella, F., \& Carli, G. (1993). Blood lactate accumulation in top-level swimmers following competition. Journal of Sports Medicine and Physical Fitness, 33(1), 13-18.

Burkett, B., Mellifont, R., \& Mason, B. (2010). The influence of swimming start components for selected Olympic and Paralympic swimmers. Journal of Applied Biomechanics, 26, 134-140.

Cala, A., Veiga, S., García, A., \& Navarro, E. (2009). Previous cycling does not affect running efficiency during a triathlon World Cup competition. Journal of Sport Medicine and Physical Fitness, 49, 152-158.

Chatard, J. C., Girold, S., Caudal, N., Cossor, J., \& Mason, B. (2003). Analysis of the $200 \mathrm{~m}$ events in the Sydney Olympic games. In J. C. Chatard (Ed.), Biomechanics and medicine in swimming IX (pp. 261-264). Saint Etienne: University of Saint Etienne.

Chatard, J. C., Girold, S., Cossor, J. M., \& Mason, B. R. (2001a). Specific strategy for the medallists versus finalists and semi-finalists in the men's $200 \mathrm{~m}$ backstroke at the Sydney Olympic games. In J. Blackwell \& R. H. Sanders (Eds.), Proceedings of swim sessions XIX international symposium on biomechanics in sports (pp. 27-30). San Francisco: International Society of Biomechanics in Sports.

Chatard, J. C., Girold, S., Cossor, J. M., \& Mason, B. R. (2001b). Specific strategy for the medallists versus finalists and semi finalists in the men's $200 \mathrm{~m}$ freestyle at the Sydney Olympic games. In J. Blackwell \& R. H. Sanders (Eds.), Proceedings of swim sessions XIX international symposium on biomechanics in sports (pp. 57-60). San Francisco: International Society of Biomechanics in Sports.

Chollet, D., Pelayo, P., Delaplace, C., Tourny, C., \& Sidney, M. (1997). Stroking characteristic variations in the 100-m freestyle for male swimmers of differing skill. Perceptual \& Motor Skills, 85(1), 167-177.

Cohen, R. C. Z., Cleary, P. W., \& Mason, B. R. (2012). Simulations of dolphin kick swimming using smoothed particle hydrodynamics. Human Movement Science, 31(3), 604-619.

Connaboy, C., Coleman, S., Moir, G., \& Sanders, R. H. (2010). Measures of reliability in the kinematics of maximal undulatory underwater swimming. Medicine and Science in Sports and Exercise, 42(4), 762-770.

Connaboy, C., Coleman, S., \& Sanders, R. H. (2009). Hydrodynamics of undulatory underwater swimming: A review. Sports Biomechanics, 8, 360-380.

Cossor, J. M., \& Mason, B. R. (2001). Swim start performances at the Sydney 2000 Olympic games. In Proceedings of swim sessions: XIX international symposium on biomechanics in sports June 26, 2001 (pp. 70-74). San Francisco: Department of Exercise \& Sport Science, University of San Francisco.

de Jesus, K., de Jesus, K., Figueiredo, P. A., Gonçalves, P., Vilas-Boas, J., \& Fernandes, R. J. (2012). Effects of fatigue on kinematical parameters during submaximal and maximal 100-m butterfly bouts. Journal of Applied Biomechanics, 28(5), 599-607.

Figueiredo, P., Rouard, A., Vilas-Boas, J., \& Fernandes, R. J. (2013). Upper- and lower-limb muscular fatigue during the 200-m front crawl. Applied Physiology, Nutrition \& Metabolism, 38(7), 716-724.

Figueiredo, P., Zamparo, P., Sousa, A., Vilas-Boas, J., \& Fernandes, R. (2011). An energy balance of the $200 \mathrm{~m}$ front crawl race. European Journal of Applied Physiology, 111(5), 767-777.

Hellard, P., Dekerle, J., Avalos, M., Caudal, N., Knopp, M., \& Hausswirth, C. (2008). Kinematic measures and stroke rate variability in elite female 200-m swimmers in the four swimming techniques: Athens 2004 Olympic semi-finalists and French National 2004 Championship semi-finalists. Journal of Sports Sciences, 26(1), 35-46. 
Hiley, M. J., Zuevsky, V., \& Yeadon, M. R. (2013). Is skilled technique characterized by high or low variability? An analysis of high bar giant circles. Human Movement Science, 32(1), 171-180.

Hochstein, S., \& Blickhan, R. (2011). Vortex re-capturing and kinematics in human underwater undulatory swimming. Human Movement Science, 30(5), 998-1007.

Houel, N., Elipot, M., André, F., \& Hellard, P. (2013). Influence of angles of attack, frequency and kick amplitude in swimmer's horizontal velocity during underwater phase of a grab start. Journal of Applied Biomechanics, 29, 49-54.

Huot-Marchand, F., Nesi, X., Sidney, M., Alberty, M., \& Pelayo, P. (2005). Variations of stroking parameters associated with $200 \mathrm{~m}$ competitive performance improvement in top-standard front crawl swimmers. Sports Biomechanics, 4(1), 89-99.

Knudson, D. (2009). Significant and meaningful effects in sports biomechanics research. Sports Biomechanics, 8(1), 96-104.

Kolmogorov, S. V., Rumyantseva, O. A., Gordon, B. J., \& Cappaert, J. M. (1997). Hydrodynamic characteristics of competitive swimmers of different genders and performance levels. Journal of Applied Biomechanics, 13(1), 88-97.

Lyttle, A. D., Blanksby, A., Elliott, B. C., \& Lloyd, D. G. (1998). The effect of depth and velocity on drag during the streamlined glide. Journal of Swimming Research, 13, 15-22.

McLean, S. P., Havriluk, R., \& Brandt, S. (2008). Effect of adding a dolphin kick to a breaststroke pullout. Medicine and Science in Sports and Exercise, 40(5 (Supplement 1)), S377.

Psycharakis, S. G., Naemi, R., Connaboy, C., McCabe, C., \& Sanders, R. H. (2010). Three-dimensional analysis of intracycle velocity fluctuations in front-crawl swimming. Scandinavian Journal of Medicine and Science in Sports, 20, 128-135.

Puel, F., Morlier, J., Avalos, M., Mesnard, M., Cid, M., \& Hellard, P. (2012). 3D kinematic and dynamic analysis of the front crawl tumble turn in elite male swimmers. Journal of Biomechanics, 45, 510-515.

Schutz, R. W., \& Gessaroli, M. E. (1987). The analysis of repeated measures designs involving multiple dependent variables. Research Quarterly for Exercise E Sport, 58, 132-149.

Seifert, L., Boulesteix, L., Carter, M., \& Chollet, D. (2005). The spatial-temporal and coordinative structures in elite male 100-m front crawl swimmers. International Journal of Sports Medicine, 26(4), 286-293.

Seifert, L., Vantorre, J., \& Chollet, D. (2007). Biomechanical analysis of the breaststroke start. International Journal of Sports Medicine, 28(11), 970-976.

Suito, H., Ikegami, Y., Nunome, H., Sano, S., Shinkai, H., \& Tsujimoto, N. (2008). The effect of fatigue on the underwater arm stroke motion in the 100-m front crawl. Journal of Applied Biomechanics, 24(4), 316-324.

Thompson, K. G., Haljand, R., \& MacLaren, D. P. (2000). An analysis of selected kinematic variables in national and elite male and female 100-m and 200-m breaststroke swimmers. Journal of Sports Sciences, 18(6), 421-431.

Tourny-Chollet, C., Chollet, D., Hogie, S., \& Papparodopoulos, C. (2002). Kinematic analysis of butterfly turns of international and national swimmers. Journal of Sports Sciences, 20(5), 383-390.

Toussaint, H. M., \& Beek, P. J. (1992). Biomechanics of competitive front crawl swimming. Sports Medicine, 13(1), 8-24.

Toussaint, H. M., Carol, A., Kranenborg, H., \& Truijens, M. J. (2006). Effect of fatigue on stroking characteristics in an arms-only $100-\mathrm{m}$ front crawl race. Medicine and Science in Sports and Exercise, 38(9), 1635-1642.

Toussaint, H. M., Roos, P. E., \& Kolmogorov, S. (2004). The determination of drag in front crawl swimmers. Journal of Biomechanics, 37(11), 1655-1663.

Vantorre, J., Seifert, L., Fernandes, R. J., Vilas Boas, J. P., \& Chollet, D. (2010a). Kinematical profiling of the front crawl start. International Journal of Sports Medicine, 31, 16-21.

Vantorre, J., Seifert, L., Fernandes, R. J., Vilas Boas, J. P., \& Chollet, D. (2010b). Comparison of grab start between elite and trained swimmers. International Journal of Sports Medicine, 31(12), 887-893.

Veiga, S., Cala, A., González Frutos, P., \& Navarro, E. (2010). The validity and reliability of a procedure for competition analysis in swimming based on individual distance measurements. XIth international symposium for biomechanics \& medicine in swimming, 11, 182-184.

Veiga, S., Cala, A., Mallo, J., \& Navarro, E. (2013). A new procedure for race analysis in swimming based on individual distance measurements. Journal of Sports Sciences, 31, 159-165.

Vennell, R., Pease, D., \& Wilson, B. (2006). Wave drag on human swimmers. Journal of Biomechanics, 39(4), 664-671.

Von Loebbecke, A., Mittal, R., Fish, F., \& Mark, R. (2009). A comparison of the kinematics of the dolphin kick in humans and cetaceans. Human Movement Science, 28(1), 99-112.

Von Loebbecke, A., Mittal, R., Mark, R., \& Hahn, M. (2009). A computational method for analysis of underwater dolphin kick hydrodynamics in human swimming. Sports Biomechanics, 8(1), 60-77.

Wakayoshi, K., D’Acquisto, L. J., Cappaert, J. M., \& Troup, J. P. (1995). Relationship between oxygen uptake, stroke rate and swimming velocity in competitive swimming. International Journal of Sports Medicine, 16(1), 19-23.

Wakayoshi, K., Yoshida, T., Ikuta, Y., Mutoh, Y., \& Miyashita, M. (1993). Adaptations to six months of aerobic swim training. Changes in velocity, stroke rate, stroke length and blood lactate. International Journal of Sports Medicine, 14(7), 368-372.

Wilson, C., Simpson, S. E., Van Emmerik, R. A., \& Hamill, J. (2008). Coordination variability and skill development in expert triple jumpers. Sports Biomechanics, 7(1), 2-9.

Zamparo, P., Vicentini, M., Scattolini, A., Rigamonti, M., \& Bonifazi, M. (2012). The contribution of underwater kicking efficiency in determining "turning performance" in front crawl swimming. The Journal of Sports Medicine and Physical Fitness, 52(5), 457-464. 